\title{
Does Social Interaction destablise Financial Markets? ${ }^{\text {th }}$
}

\author{
Frederik König \\ Faculty of Business Administration and Economics \\ Goethe-University \\ Frankfurt/Main \\ fkoenig@wiwi.uni-frankfurt.de
}

\begin{abstract}
With this paper, I propose a simple asset pricing model that accounts for the influence from social interaction. Investors are assumed to make up their mind about an asset's price based on a forecasting strategy and its past profitability as well as on the contemporaneous expectations of other market participants. Empirically analysing stocks of the DAX30 index, I provide evidence that social interaction rather destabilises financial markets. Based on my results, I state that at least, it does not have a stabilising effect.
\end{abstract}

Keywords: Asset Pricing, Social Interaction, (De-)stabilisation JEL: A14, D83, G11, G23

\footnotetext{
${ }^{\sqrt{4}}$ I would like to acknowledge Prof. Dr. Horst Entorf for a great support and constructive criticism. Further thanks go to my colleagues at the Chair of Econometrics for fruitful discussions.
} 


\section{Introduction}

In 2008, the DAX30 index fell by more than 40\%. The market capitalisation of the underlying companies declined by 380 bln $€$. In the subsequent year, however, the DAX30 index caught up roughly 25\% although the economy still was in a sever crisis. Stock price fluctuations with exaggerations like these make it hard to believe that market prices only reflect fundamental valuations as postulated by the efficient market hypothesis (Fama, 1970).

Therefore, the literature of behavioural finance proposed a variety of asset pricing models considering bounded rationally acting investors. ${ }^{1}$ All these models have in common that they deviate from the rather unrealistic statement that all investors have homogeneous beliefs about the asset price. The assumption of heterogeneous beliefs allows describing those asset price variations that are not related to an underlying process of fundamental information.

The interaction among investors with heterogeneous beliefs generally transmits via the market pricing mechanism. However, it is also reasonable to consider a direct influence through observation or communication. There is already large empirical evidence that confirms the existence and influence of such social interaction in financial markets. A general herding tendency of institutional investors has first been found by Lakonishok et al. (1992). Their seminal empirical herding measure has thereafter been applied in many studies providing similar evidence. ${ }^{2}$ Regarding the communication among institutional investors, positive evidence of influential effects has been provided by Shiller and Pound (1989); Arnswald (2001); Hong et al. (2005); Pareek (2011). In the domain of individual investors, analogous behaviour has been revealed by Hong et al. (2004); Ivkovic and Weisbenner (2007); Massa and Simonov (2005a,b).

With this paper, I intend to answer the question whether social interaction among investors causes large deviations from the fundamental benchmark

\footnotetext{
${ }^{1}$ Examples include Beja and Goldman (1980); Kyle (1985); Day and Huang (1990); Long et al. (1990); Chiarella (1992); Föllmer and Schweizer (1993); Lux (1995); Brock and Hommes (1998); Kurz (1998); Iori (2002); Chiarella et al. (2003); de Grauwe and Grimaldi (2004); Horst (2005); Föllmer et al. (2005); Dieci et al. (2006); Cipriani and Guarino (2008); Huang et al. (2010). Extensive surveys are provided by Hommes (2006); LeBaron (2006).

${ }^{2}$ See Frey et al. (2006) for a brief survey of studies that used the measure of Lakonishok et al. (1992).
} 
and thereby destabilises financial markets. There are situations where social interaction does not have any effect, irrespective of its intensity. If for instance, investors a priori all have homogeneous beliefs about an asset's price, then social influence would not affect their behaviour at all. Moreover, even if beliefs are heterogeneous, social interaction can still be without effect, if the influence is symmetric. This can be explained as follows. Symmetric social influence refers to the situation where every investor influences every other investor with equal intensity. It thereby makes investors' beliefs more homogeneous and reduces the variance of opinions. However, it does not change the average opinion. In a sufficiently liquid market, where the asset price more or less reflects the average opinion about an asset's value, social influence thus has no effect. Given these facts, I propose an asset pricing model where investors have heterogeneous beliefs and the influence from social interaction among these investors is allowed to be asymmetric. Particularly, I make use of the well-known adaptive beliefs model of Brock and Hommes $(1997,1998)$ and enrich it by the inclusion of social influence. In order to empirically analyse the impact of social interaction, I presume the existence of two investor types, fundamentalists and chartists, who a priori either have a stabilising or a destabilising effect on financial markets. ${ }^{3}$ I then contrast the original model of Brock and Hommes (1998) with my extended version that accounts for asymmetric social influence. If the null hypothesis of symmetric social influence can be rejected, then it can be concluded that social interaction has an impact. The sign of the estimated difference between social influence on fundamentalists and chartists indicates whether this impact rather is stabilising or destabilising.

With this paper, I contribute to the literature that empirically analyses price impacts of social interaction, particularly herding behaviour among investors. On the basis of quarterly stock holdings, Lakonishok et al. (1992); Jones et al. (1999); Wermers (1999); Sias (2004) provide empirical evidence that the herding behaviour of institutional investors is information driven and thus rather stabilises the market. This is in line with the results of Nofsinger and Sias (1999), who raise the same conclusion on the basis of institutional

\footnotetext{
${ }^{3}$ Note that e.g. Huang et al. (2010) proposes a framework where chartists might have both a destabilising as well as a stabilising effect. The definitions of fundamentalists and chartists in this paper, however, are chosen in a way such that fundamentalists always drive stock prices towards the fundamental benchmark, whereas chartists always drive the stock price away from it.
} 
investors' annually stock holdings. On a semi-annually basis, Walter and Weber (2006) show that for the German market institutional herding at least does not have a destabilising effect. However, differentiating between herding on buy and sell decisions, San (2007) on a quarterly basis finds a destabilising tendency for institutional sell herding. Analysing shorter time intervals, Puckett and Yan (2008) similarly show that institutional herding on stock sales, which are inferred on weekly portfolio changes, indeed may destabilise markets and thereby cause short-term fluctuations. Considering intra-day trades, Hsieh (2012) concludes for the Taiwan stock market that herding behaviour of institutional investors rather stabilises while the same behaviour of individual investors rather destabilises the market. All afore cited papers have in common that the effect on stock prices are inferred from subsequent stock returns. A stock return reversal is interpreted as a destabilising effect. Contrarily, my approach offers the possibility to directly infer the effect of social interaction from the estimates of the model parameters. Moreover, I do not classify investors into institutional and individual investors as I state that there might be investors of both categories, who either stabilise or destabilise market prices. Therefore, I follow the literature about heterogeneous agents on financial markets and assume the existence of two representative investor types: fundamentalists, who believe that stock prices revert to a fundamental benchmark and chartists, who extrapolate trends that move the stock price away from its fundamental value.

My paper is further related to the upcoming literature that is engaged in the empirical investigation of non linear asset pricing models. An early contribution has been provided by Shiller (1984), who by linear regression estimates a stock pricing model with two heterogeneous investor types, namely smart money investors with rational expectations and ordinary investors. Vigfusson (1997) uses a Markov regime-switching technique to estimate the exchange rate model of Frankel and Froot (1988) with two representative investor types, namely fundamentalists and chartists. Westerhoff and Reitz (2003) and ap Gwilym (2008) use non linear estimation techniques to estimate exchange rate models with the same representative investor types. Using the method of simulated moments, Franke (2009) estimates the exchange rate model of Manzan and Westerhoff (2005) for both stock indices and exchanges rates. Considering social interaction, Gilli and Winker (2003) and Alfarano et al. (2005) estimate Kirman's herding model (Kirman, 1993) again with afore mentioned two representative investor types. Although, Alfarano et al. (2005) account for an asymmetric autonomous switching ten- 
dency for an individual investor to change his type, both Gilli and Winker (2003) and Alfarano et al. (2005) consider symmetric influence from social interaction. Franke (2008); Lux (2012) also take the influence from social interaction into account. Therefore, they estimate the relation between stock price returns and an underlying opinion index. My paper is most strongly related to Boswijk et al. (2007) and Amilon (2008), who estimate the model of Brock and Hommes (1998), however, in its original form, i.e. without the inclusion of social interaction.

In this paper, I analyse the price evolution of the stocks that were included in the DAX30 index as of Dec $31^{\text {st }} 2010$. For 12 out of 30 stocks, the null hypothesis of the original model can be rejected. This suggests the presence of asymmetric influence from social interaction. The parameter estimates indicate that fundamentalists are more prone to be socially influenced by other market participants than chartists. This means fundamentalists skew their beliefs more strongly to those of the chartist than past performance of the strategy would suggest. Therefore, I conclude that if social interaction has an influence on stock prices, then this influence represents a destabilising impact.

The remainder of the paper is structured as follows. In chapter 2, I review the literature about asset pricing models that consider the influence from social interaction. I present my asset pricing model and derive conditions for the existence of equilibria in chapter 3. In chapter 4, I empirically estimate the model and contrast it with the original model of Brock and Hommes (1998). Chapter 5 concludes.

\section{Literature review}

The literature of behavioural finance brought out a variety of theoretical asset pricing models that take the influence from social interaction into account. There are two general types of models which have evolved. On the one hand, authors of so called heterogeneous agent models assume a small amount of groups that are formed by investors with representative investment behaviour. On the other hand, the computationally more challenging agent based models account for every investor's individual behaviour. While the latter type offers the possibility to model asset price fluctuation based on the very micro level, the advantage of the former type is the mathematical tractability such that in most cases closed form solutions can be derived. Hommes (2006) and LeBaron (2006) provide a comprehensive survey of the 
two concepts. Surveys of asset pricing models that take the influence from social interaction into account have been provided by Hirshleifer and Teoh (2008); Lux (2009).

An early example of heterogeneous agent models considering social influence is represented by Lux (1995), who proposes a framework that is based on the "ant"-model of Kirman (1993). He assumes that there are two types of investors in the market, namely fundamentalists and chartists. Chartists are either optimistic and expect price increases or they are pessimistic and expect the price to decrease. The probability that a chartist changes his belief from optimistic to pessimistic or vice versa on the one hand depends on an idiosyncratic component and on the other hand is related to the portion of chartists in the market that have a particular either optimistic or pessimistic expectation. By the second factor a direct influence from social interaction is introduced. Simulation results of Lux (1995) show that the model is capable to reproduce stylised facts which can be observed in financial markets. In Lux (1998), the model is extended by a learning mechanism to switch between the fundamental and chartist strategy. The work of Alfarano et al. (2008) is closely related to the two afore cited papers. Contrarily, Alfarano et al. (2008) assume that social influence does not only depend on the relative portion of market participant following a particular strategy, but on the explicit group sizes and therefore also on the absolute number of market participants.

Providing an alternative model, Chiarella et al. (2003) assume that investors follow either a fundamentalist strategy or are herding agents. The latter infer their beliefs from past excess demand in the market and therefore are affected by a direct social influence from other market participants.

Horst (2005); Wu (2007); Horst and Rothe (2008) state that investors choose between a fundamentalist and chartist strategy depending on which strategy they expect that the majority of the whole market will adopt ("market mood"). Horst (2005) moreover takes the influence from the observable choice of the nearest neighbours into account. Working with fundamentalists and noise trades, Pakkanen (2009) proposes an asset pricing model where investors either trade the asset or revise their belief, i.e. change their type. When an investor trades the asset, the decision whether to buy or sell it depends on his own prior belief and the general market mood, which represents a compound measure of all individual investors' beliefs.

Most closely related to this paper, Chang (2007) uses the model of Brock and Hommes (1998) and introduces the influence from social interaction into 
the mechanism of investor's switching between a fundamental and a chartist strategy. The social influence is modelled by the framework of Brock and Durlauf (2001b,a). Different to Chang (2007), I account for an asymmetric social influence while switching from one strategy to another. Moreover, I assume that social influence induces an investor to skew his beliefs towards the beliefs of other investors without completely rejecting the own and adopting an alternative strategy.

In the domain of agent based models, one of the first contributions in the context of social interaction has been provided by Baker and Iyer (1992). They assume that investors randomly receive exogenous buy or sell signals and transmit them via a communication network. If an investor by inter-investor transmission receives an equal number of buy and sell signals, these signals cancel out each other, such that the particular investor does not trade at all. Simulation results show that the topology of this network has a considerable effect on price volatility and trading volume.

Cont and Bouchaud (2000) propose a framework where investors within the same neighbourhood always make the same trading decisions. All neighbourhoods are isolated. The size of these clusters is obtained by a random graph. Iori (2002) also states that investors are influenced by the trades of neighbouring investors. However, an individual investor's choice does not necessarily coincide with those of his neighbours. Instead, an individual decision is made based on the weighted average decision of neighbouring investors within a lattice network as well as on an idiosyncratic component.

Proposing an explicit function for the process of investors' information elaboration, Schütz et al. (2009) construct a theoretical framework where investors build up exogenous sell or buy signals based on the difference between their own fundamental valuation of the asset and the current market price. An investor's decision whether to buy or to sell an asset then depends on the own signal and the weighted average of neighbouring investors' demands.

While afore cited authors, only assumed that an individual investor is influenced by other investors' actions, i.e. trading decisions, Ozsoylev (2006) and Ozsoylev and Walden (2011) state that social networks permit the transmission of information such that better connected investors have more precise information. Social influence in this case is not based on other investors' outcomes, but on their original information signals.

In the same vein, Panchenko et al. (2010) state that well connected investors are better off. Particularly, like in this paper, they consider the heterogeneous agent model of Brock and Hommes (1998). However, in their frame- 
work, investors can only observe the past profitability of a strategy, if there are investors in the neighbourhood who adopted this strategy in the past. This means for instance, an investor is unable to get to know the profitability of the chartist strategy if he is only surrounded by fundamentalists. The difference to my approach is that I assume that real markets offer a minimum of transparency that makes it possible to observe the past profitability of all strategies. Social influence in my framework thus only affects the elaboration of the information that is available to every market participant.

Also based on the assumption of information transmission within a social network, Colla and Mele (2010) propose a framework where trades are pos-

itively correlated if investors are located nearby because of the exchange of information and trades are negatively correlated if investors are further away acting as counterparties in the market clearing mechanism.

The approach of Kaizoji (2000) originally stems from the domain of agent based models. For the sake of an empirical analysis however, the underlying social network is simplified such that analytical tractability as in heterogeneous agent models is obtained. Investors are supposed to be either willing to buy or willing to sell the asset. An investor bases his decision on the general market environment and furthermore is directly influenced by the contemporaneous asset demand of other investors in the market.

With my approach, I set up on a heterogeneous agent model that trough the inclusion of social influence becomes an agent based model offering the possibility to account for every individual investor's behaviour. However, in order to ensure analytical tractability, which is needed for the empirical analysis, I simplify the structure of the underlying social network and thereby again obtain a heterogeneous agent model.

\section{Asset pricing in the presence of social interaction}

In the following, I present the model of Brock and Hommes (1998) and enrich it by an influential component based on social interaction among investors.

\subsection{Market price mechanism}

Considering a market with one risky and one riskless asset, investors are confronted to the decision how to allocate their present wealth in order to maximise next period's wealth, which is given by

$$
W_{i, t+1}=(1+r) W_{i, t}+\left(p_{t+1}+y_{t+1}-(1+r) p_{t}\right) z_{i t},
$$


where $p_{t}$ and $p_{t+1}$ are this period's and next period's market price of the risky asset that pays an uncertain dividend $y_{t+1}$. The return of the risk free asset with perfectly elastic supply is given by $r$. An investor's individual demand for the risky asset equals $z_{i t}$. Investors are assumed to be myopic mean-variance optimisers, such that $z_{i t}$ results from

$$
\max _{z_{i t}} \mathrm{E}_{i t}\left[W_{i, t+1}\right]-\frac{a_{i t}}{2} \operatorname{Var}_{i t}\left[W_{i, t+1}\right]
$$

where $\mathrm{E}_{i t}$ and $\operatorname{Var}_{i t}$ are an investor's conditional expectation and variance at time $t$ and $a_{i t}$ stands for an investor's constant average risk aversion. In order to keep the model analytically tractable, Brock and Hommes (1998) introduced the following assumptions:

$$
\begin{aligned}
\operatorname{Var}_{i t}\left[W_{i, t+1}\right] & :=\sigma^{2} \\
a_{i t} & :=a .
\end{aligned}
$$

This means that the conditional variance about next period's wealth and the coefficient of risk aversion are presumed to be constant among investors as well as in time. The resulting demand of an individual investor is hence given by

$$
z_{i t}=\frac{\mathrm{E}_{i t}\left[p_{t+1}+y_{t+1}-(1+r) p_{t}\right]}{a \sigma^{2}} .
$$

The model is closed by the following market clearing equation

$$
\sum_{i} z_{i t}=L_{t}
$$

where $L_{t}$ is the contemporaneous net supply of the risky asset. Plugging equation 5 into equation 6 and solving for $p_{t}$ yields

$$
p_{t}=\frac{1}{1+r}\left(\sum_{i} \mathrm{E}_{i t}\left[p_{t+1}+y_{t+1}\right]-a \sigma^{2} L_{t}\right) .
$$

It is possible to derive the fundamental equilibrium, which is arises when all investors have homogeneous beliefs, i.e. have the same conditional expectation about the risky asset:

$$
p_{t}^{*}=\frac{1}{1+r}\left(\mathrm{E}_{t}\left[p_{t+1}^{*}+y_{t+1}\right]-a \sigma^{2} L_{t}\right)
$$


The fundamental price is indicated by a star. Subtracting equation 8 from equation 7 offers the possibility to express the price equation as deviations from the fundamental price:

$$
x_{t}=\frac{1}{1+r} \sum_{i} \mathrm{E}_{i t}\left[x_{t+1}\right],
$$

with $x_{t}=p_{t}-p_{t}^{*}$. Please note that equation 9 contains the implicit assumption that dividends follow a stochastic process with constant temporal mean. For notational convenience, an investor's beliefs about next period's deviation from the fundamental value are henceforth denoted by $f_{i t}$, i.e.

$$
f_{i t}=\mathrm{E}_{i t}\left[x_{t+1}\right]
$$

\subsection{Heterogeneous beliefs and social interaction}

An investor is assumed to make up his beliefs about future deviations of the market price from the fundamental benchmark based on two sources. On the one hand, he considers his own a priori expectation. On the other hand and additionally to the original model of Brock and Hommes (1998), I assume that he also takes into account the beliefs of other market participants. In order to consider the influence from this social interaction, I make use of the linear model from the social interaction literature (e.g. Manski (1993); Moffitt (2001); Bramoullé et al. (2009); Blume et al. (2010); Lee et al. (2010)): ${ }^{4}$

$$
f_{i t}=\theta_{i t}+\delta_{i}\left(\sum_{j \neq i} \gamma_{i j} f_{j t}-\theta_{i t}\right),
$$

where $\theta_{i t}$ represents the expectation of the future deviation from the fundamental benchmark that an investor makes up on his own. The coefficient $\delta_{i}$ measures the magnitude of social influence. Every other investor's influence is weighted with $\gamma_{i j} \geq 0$. Ensuring that $\delta_{i}$ captures the total magnitude of influence, the following constraint shall be imposed:

$$
\sum_{j \neq i} \gamma_{i j} \stackrel{!}{=} 1
$$

\footnotetext{
${ }^{4}$ Contrary to the social interaction literature, I do not consider contextual effects, i.e. the influence of an individual's characteristics on the outcome of an other individual, as it is unlikely that an investor's beliefs are influenced by the background of another investors.
} 
In order to avoid a general upward bias of an investor's beliefs $f_{i t}$ through the inclusion of influence from social interaction, only the difference between the weighted average of other investor's beliefs and an investor's own a priori expectation is considered in equation $11 .^{5}$

The values of the coefficient of social interaction $\delta_{i}$ can be interpreted as follows. If $0<\delta_{i}<1$, then an investor skews his initial expectation towards the expectation of other investors. The resulting expectation then represents a weighted average of the own initial and other investors' beliefs. This situation shall be henceforth referred as moderate social influence. For $\delta_{i}=0$, an investor is not influenced by other investors at all, whereas for $\delta_{i}=1$, an investor completely rejects his own a priori expectation and adapts the weighted beliefs of other investors. It is also possible that an investor is such strongly influenced that he skews his own expectation even beyond those of other investors. In this case, henceforth denoted extreme social influence, $\delta_{i}$ can take values greater than one. Values below zero are not considered for $\delta_{i}$ as this would represent a negative influence from social interaction. Indeed, arbitrageurs might act as contrarians and therefore have opposite beliefs. This however represents a form of influence which translates through the market price mechanism and hence cannot be understood as a direct influence from social interaction.

The integration of social influence into the original model of Brock and Hommes (1998) could lead to infeasible solutions for the asset price depending on the values of $\delta_{i}$. The following propositions state, under which conditions the existence of exactly one equilibrium price is ensured.

Proposition 1: If all investors are only moderately influenced by other investors $\left(\delta_{i}<1\right)$, then exactly one feasible market equilibrium arises from equation 9.

The proof is given in the appendix A.2. Proposition 1 shows that for an arbitrary structure of the underlying social network, there exists always an equilibrium, if social influence is moderate. Having a closer look at the particular network structure where every investor equally weights other in-

\footnotetext{
${ }^{5}$ In the social interaction literature, this difference is generally not considered, such that stronger social influence leads to higher outcomes (Glaeser and Scheinkman, 2001; Glaeser et al., 2003). Such a social multiplier is however not reasonable in this context, as social influence can be assumed to drive asset prices into both directions.
} 
vestors' beliefs, proposition 2 and 3 state under which conditions the presence of extreme social influence still leads to feasible model solutions. The structure of equal weights is very convenient as it ensures analytical tractability, which is needed for the empirical analysis later in this paper.

Proposition 2: Suppose that there are $N$ investors who all equally weight other investors' beliefs $\left(\gamma_{i j}=\frac{1}{N-1}\right)$ and that at least two investors are only moderately influenced by other investors $\left(\delta_{i}<1\right)$. If for all investors that are extremely influenced $\left(\delta_{i}>1\right)$, the magnitude of influence does not reach or exceed an upper bound given by $\delta_{i}<\frac{N-1}{\sum_{j \neq i} \min \left\{\delta_{j}, 1\right\}}$, then exactly one feasible market equilibrium arises from equation 9.

Appendix A.3 provides the proof of this proposition. In order to restrict the number of degrees of freedom in the empirical analysis, only two representative investor types and a large number of investors are considered. The following proposition derives the equilibrium condition for this constellation still assuming a network structure with equal weights.

Proposition 3: Assume that there are two representative investor types in a market with a large number of investors $(N \rightarrow \infty)$. Each type shall be influenced by all other investors with a particular type-specific magnitude $\left(\delta_{1}\right.$ and $\left.\delta_{2}\right)$. Suppose further that all investors equally weight other investors' beliefs $\left(\gamma_{i j}=\frac{1}{N-1}\right)$. Equation 9 yields exactly one feasible market equilibrium, if the following inequality is fulfilled: $n \delta_{1}+(1-n) \delta_{2} \neq 1$, where $n$ is the portion of investors of a particular type.

See appendix A.4 for the proof of proposition 3.

\subsection{Fundamentalists vs. chartists and adaptive beliefs}

Brock and Hommes (1998) assume that an investor infers his a priori expectation from past observations, i.e.

$$
\theta_{i t}=\Phi_{i}+\sum_{k} \Phi_{i k} x_{t-k}
$$

$\Phi_{i}$ represents an investor's constant bias compared to the fundamental benchmark. The coefficients $\Phi_{i k}$ are individual weights of past observations and define whether an investors rather has a stabilising or a destabilising effect 
on the market price. If $\Phi_{i k}<1$, then investor $i$ expects that the deviation of the asset price from its fundamental value will decrease during the next period. Therefore, he is willing to buy (sell) the asset, if its market price is below (above) the fundamental benchmark and thereby stabilises the market. Contrarily, investor $i$ believes that the market price further divagates from the fundamental equilibrium, if $\Phi_{i k}>1$. He thereby destabilises the market. In order to keep the model analytically tractable and to make an empirical analysis possible, I hereafter assume that there are only two types of investors in the market, namely fundamentalists and chartists. Mathematically, the fundamental strategy shall be defined by

$$
\begin{aligned}
\Phi_{i} & =0 \\
\Phi_{i k} & = \begin{cases}\Phi_{F}<0 & \text { if } k=1 \\
0 & \text { if } k \neq 1\end{cases} \\
\delta_{i} & =\delta_{F} \\
\gamma_{i j} & =\frac{1}{N-1},
\end{aligned}
$$

with $N$ being the total Number of investors in the market. Analogously the chartist strategy shall be given by

$$
\begin{aligned}
\Phi_{i} & =0 \\
\Phi_{i k} & = \begin{cases}\Phi_{C}>0 & \text { if } k=1 \\
0 & \text { if } k \neq 1\end{cases} \\
\delta_{i} & =\delta_{C} \\
\gamma_{i j} & =\frac{1}{N-1} .
\end{aligned}
$$

With these definitions and assuming a large number of investors $(N \rightarrow \infty)$, investors' beliefs turn out to be

$$
f_{F t}=\left(1-\delta_{F}\right) \Phi_{F} x_{t-1}+\delta_{F}\left(n_{F t} f_{F t}+n_{C t} f_{C t}\right)
$$

and

$$
f_{C t}=\left(1-\delta_{C}\right) \Phi_{C} x_{t-1}+\delta_{C}\left(n_{F t} f_{F t}+n_{C t} f_{C t}\right),
$$

where $n_{F t}$ and $n_{C t}$ are the portions of investors in the market who either follow the fundamental or the chartist strategy. As only two investor types 
are assumed, the portion of chartists can be expressed by $n_{C t}=1-n_{F t}$. Equations 24 and 25 can be written as

$$
f_{F t}=\frac{\left(1-\delta_{F}\right)\left(1-\delta_{C}\left(1-n_{F t}\right)\right) \Phi_{F} x_{t-1}+\delta_{F}\left(1-\delta_{C}\right)\left(1-n_{F t}\right) \Phi_{C} x_{t-1}}{1-\delta_{F} n_{F t}-\delta_{C}\left(1-n_{F t}\right)}
$$

and

$$
f_{C t}=\frac{\left(1-\delta_{C}\right)\left(1-\delta_{F} n_{F t}\right) \Phi_{C} x_{t-1}+\delta_{C}\left(1-\delta_{F}\right) n_{F t} \Phi_{F} x_{t-1}}{1-\delta_{F} n_{F t}-\delta_{C}\left(1-n_{F t}\right)} .
$$

Plugging equations 24 and 25 into equation 9 yields

$$
\begin{aligned}
x_{t} & =\frac{1}{1+r}\left(n_{F t} \frac{\left(1-\delta_{F}\right)\left(1-\delta_{C}\left(1-n_{F t}\right)\right) \Phi_{F} x_{t-1}+\delta_{F}\left(1-\delta_{C}\right)\left(1-n_{F t}\right) \Phi_{C} x_{t-1}}{1-\delta_{F} n_{F t}-\delta_{C}\left(1-n_{F t}\right)}\right. \\
& \left.+\left(1-n_{F t}\right) \frac{\left(1-\delta_{C}\right)\left(1-\delta_{F} n_{F t}\right) \Phi_{C} x_{t-1}+\delta_{C}\left(1-\delta_{F}\right) n_{F t} \Phi_{F} x_{t-1}}{1-\delta_{F} n_{F t}-\delta_{C}\left(1-n_{F t}\right)}\right) \\
& =\frac{1}{1+r} \frac{\left(1-\delta_{F}\right) n_{F t} \Phi_{F} x_{t-1}+\left(1-\delta_{C}\right)\left(1-n_{F t}\right) \Phi_{C} x_{t-1}}{1-\delta_{F} n_{F t}-\delta_{C}\left(1-n_{F t}\right)} .
\end{aligned}
$$

Investors are assumed to choose a strategy based on its past profitability ("adaptive beliefs"). In this context, however, they do not consider effects of social interaction in the past. Hence, I presume that they do not take into account that they would have been influenced by other investors while choosing a particular strategy. The last period's profitability of a strategy $\pi_{t-1}$ is obtained by the multiplication of the return $R_{t-1}$ which would have been realised in the last period $t-1$, with the corresponding hypothetical quantity $z_{t-2}$ being bought or sold at $t-2$, if this particular strategy had been chosen at $t-2$, i.e.

$$
\pi_{t-1}=R_{t-1} z_{t-2}
$$

The profitability of the fundamental strategy is given by

$$
\begin{aligned}
\pi_{F, t-1} & =\left(x_{t-1}-(1+r) x_{t-2}\right) \frac{E_{F, t-2}\left[x_{t-1}\right]-(1+r) x_{t-2}}{a \sigma^{2}} \\
\pi_{F, t-1} & =\left(x_{t-1}-(1+r) x_{t-2}\right) \frac{\Phi_{F} x_{t-3}-(1+r) x_{t-2}}{a \sigma^{2}} .
\end{aligned}
$$

Analogously the profitability of the chartist strategy turns out to be

$$
\pi_{C, t-1}=\left(x_{t-1}-(1+r) x_{t-2}\right) \frac{\Phi_{C} x_{t-3}-(1+r) x_{t-2}}{a \sigma^{2}} .
$$


An investor's utility as a function of the realised profitability shall be given by

$$
U_{i t}=\pi_{t-1}+\epsilon_{i t},
$$

where $\epsilon_{i t}$ is an individual investor's identically independently distributed error when perceiving the profitability of a particular strategy. This noise term is assumed to be drawn from a double exponential distribution. As the number of investors goes to infinity, the portion of investors in the market that follow the fundamental strategy turns out to be

$$
\begin{aligned}
n_{F t} & =\frac{e^{\beta \pi_{F, t-1}}}{e^{\beta \pi_{F, t-1}}+e^{\beta \pi_{C, t-1}}} \\
& =\frac{1}{1+e^{-\beta\left(\pi_{F, t-1}-\pi_{C, t-1}\right)}},
\end{aligned}
$$

where $\beta$ is the intensity of choice measuring investors' tendency to choose the strategy which has better performed in the past. For $\beta=0$, investors do not take into account past profitability at all. As $\beta$ goes towards infinity, investors always choose the strategy with the highest past profitability. Please note that the switching mechanism is symmetric. Hence, the probability for choosing a particular strategy only depends on the strategy's past profitability and not on the strategy itself. Plugging equations 29 and 30 into equation 33 yields

$$
n_{F t}=\frac{1}{1+e^{-\beta\left(\left(x_{t-1}-(1+r) x_{t-2}\right) \frac{\left(\Phi_{F}-\Phi_{C}\right) x_{t-3}-(1+r) x_{t-2}}{a \sigma^{2}}\right)}} .
$$

\section{Empirical analysis}

The purpose of this paper is to empirically investigate, whether the influence of social interaction has a stabilising or a destabilising effect on financial markets. The estimation equations of the non linear adaptive beliefs model presented in the previous chapter are given by

$$
\begin{aligned}
x_{t} & =\frac{1}{1+r} \frac{\left(1-\delta_{F}\right) n_{F t} \Phi_{F} x_{t-1}+\left(1-\delta_{C}\right)\left(1-n_{F t}\right) \Phi_{C} x_{t-1}}{1-\delta_{F} n_{F t}-\delta_{C}\left(1-n_{F t}\right)}+\epsilon_{t} \\
n_{F t} & =\frac{1}{1+e^{-\beta^{*}\left(x_{t-1}-(1+r) x_{t-2}\right)\left(\Phi_{F}-\Phi_{C}\right) x_{t-3}-(1+r) x_{t-2}}},
\end{aligned}
$$


with $\beta^{*}=\frac{\beta}{a \sigma^{2}}$. Reformulating equation 35 yields

$$
x_{t}=\frac{1}{1+r} \frac{n_{F t} \Phi_{F} x_{t-1}+\left(1-n_{F t}\right) \Phi_{C} x_{t-1}-\frac{\Delta \delta}{1-\delta_{C}} n_{F t} \Phi_{F} x_{t-1}}{1-\frac{\Delta \delta}{1-\delta_{C}} n_{F t}}+\epsilon_{t},
$$

with $\Delta \delta=\delta_{F}-\delta_{C}$. Thereof, it follows that the absolute values of the coefficients of social interaction $\delta_{F}$ and $\delta_{C}$ are not directly identifiable. However, this doesn't matter, because only the difference between $\delta_{F}$ and $\delta_{C}$ is of interest, as only asymmetric social influence, i.e. $\Delta \delta \neq 0$ irrespective of the absolute values of $\delta_{F}$ and $\delta_{C}$, can have an impact on asset prices. Indeed, for $\Delta \delta=0$ equation 37 reduces to the original model of Brock and Hommes (1998).

If the estimate of $\Delta \delta^{*}=\frac{\Delta \delta}{1-\delta_{C}}$ turns out to be significantly different from zero, it can be concluded that social interaction has an impact on the asset price. Stated differently, if $\Delta \delta^{*} \neq 0$, the model fit is better, if social influence is taken into account, because there are deviations from the fundamental benchmark which are caused by the influence of social interaction.

Regarding the implications of different values for $\Delta \delta^{*}$, figure 1 shows that for $\Delta \delta^{*}>1$ either $\delta_{F}>1$ and $\delta_{C}<1$ or $\delta_{F}<1$ and $\delta_{C}>1$. Hence, if $\Delta \delta^{*}$ is greater than one, then either fundamentalists or chartsists are extremely influenced by social interaction. If $\Delta \delta^{*}<1$, then it follows that $\delta_{F}<1$ and $\delta_{C}<1$, because the case where $\delta_{F}>1$ and $\delta_{C}>1$ shall be excluded, as it would imply that all investors are extremely influenced by social interaction. This doesn't make sense, because in such a situation fundamentalists would just become chartists and vice versa. Hence, if $\Delta \delta^{*}$ is smaller than one, all investors are only moderately influenced by social interaction.

In order to disentangle, whether social interaction has a stabilising or destabilising effect on financial markets, one has to look at the sign of the estimated coefficient $\Delta \delta^{*}$. Figure 1 confirms that as long as $\Delta \delta^{*}$ is smaller than one, the sign of $\Delta \delta$ corresponds to the sign of $\Delta \delta^{*}$. If $\Delta \delta$ turns out to be positive, then investors following the fundamental strategy skew their opinion more strongly towards the opinion of investors following the chartist strategy and vice versa, if $\Delta \delta$ is negative. Hence, $\Delta \delta>0$ indicates that social interaction has a destabilising effect, while $\Delta \delta<0$ suggests that social interaction rather stabilises the market.

I estimate the model by non linear least squares regression for all stocks that were included in the DAX30 as of Dec $31^{\text {st }} 2010$. For the preceding seven years time period, i.e. from Jan $1^{\text {st }} 2004$ to Dec $31^{\text {st }} 2010$, I retrieved daily 
Figure 1: Relationship between $\delta_{F}$ and $\delta_{C}$

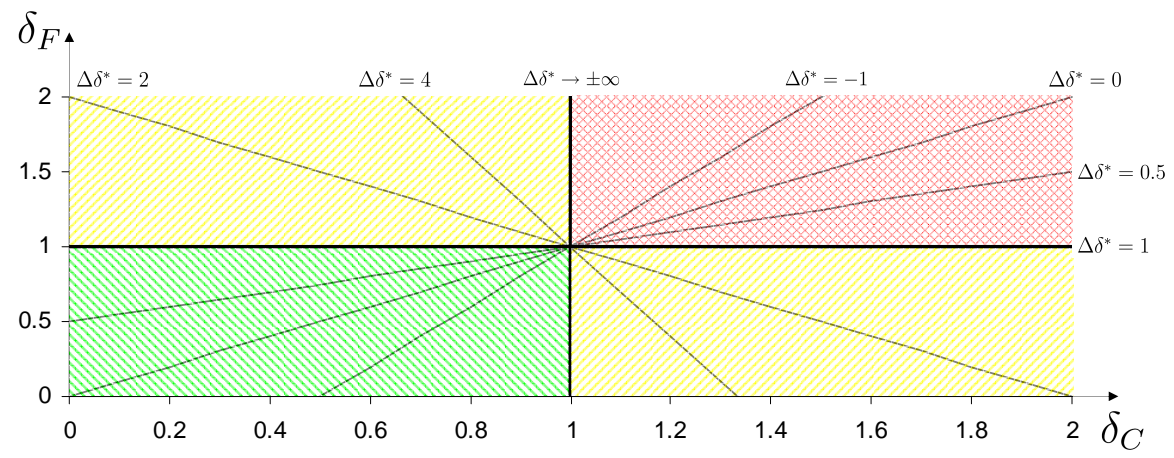

The figure displays the relationship between $\delta_{F}$ and $\delta_{C}$ for different values of $\Delta \delta^{*}=\frac{\Delta \delta}{1-\delta_{C}}$.

closing prices from Thomson Reuters. The choice of the time window is very convenient, as it captures the economic upturn until 2006 as well as the financial and economic crisis starting in 2007. In order to have a fundamental benchmark, I furthermore collected analysts' consensus price targets from the I/B/E/S database also provided by Thomson Reuters. The difference between the stock price and analysts' opinions about a stock's fair value represents the deviation from the fundamental benchmark, denoted by $x_{t}$ in the model. For several reasons, analysts' predictions are biased. ${ }^{6}$ In order to account for this fact, I demeaned the stocks' time series of deviations. Moreover, I considered weekly averages in order to suppress very short-term fluctuations. The weekly risk-free rate $r$ is obtained from the yield curve of German government bonds as published on the homepage of the Deutsche Bundesbank. $^{7}$

The results for all 30 stocks are given in table 1. It can be seen that without imposing any restriction on $\Phi_{F}$ and $\Phi_{C}$, the estimate of $\Phi_{F}$ is smaller than one and the estimate of $\Phi_{C}$ is greater than one for all 30 stocks, such that the definitions of fundamentalists and chartists are met. Also remarkably, all estimates of $\Delta \delta^{*}$ are smaller than one. This implies that no investor is extremely influenced by social interaction. Moreover, the model always yields a feasible market equilibrium price as stated by the propositions in chapter 3.2. For 16 out of 30 stocks, the estimate of $\Delta \delta^{*}$ is significantly different

\footnotetext{
${ }^{6}$ See for instance Graham (1999); Hong et al. (2000); Welch (2000); Cooper et al. (2001); Hong and Kubik (2003); Bernhardt et al. (2006); Chen and Jiang (2006); Clarke and Subramanian (2006); Naujoks et al. (2009); Jegadeesh and Kim (2010)

${ }^{7}$ See www.bundesbank.de
} 
Table 1: Estimation results

\begin{tabular}{|c|c|c|c|c|c|}
\hline & $\Delta \delta^{*}$ & $\beta^{*}$ & $\Phi_{F}$ & $\Phi_{C}$ & $R_{a d j}^{2}$ \\
\hline ADIDAS AG & $\begin{array}{l}0,6501^{* * *} \\
(0,020919)\end{array}$ & $\begin{array}{c}35,7675^{* * *} \\
(142,444405)\end{array}$ & $\begin{array}{l}0,9246 * * * \\
(0,000042)\end{array}$ & $\begin{array}{l}1,0387 * * * \\
(0,000024)\end{array}$ & 0,9967 \\
\hline ALLIANZ SE & $\begin{array}{c}0,3044 \\
(0,099270)\end{array}$ & $\begin{array}{c}5,3527^{* *} \\
(4,945269)\end{array}$ & $\begin{array}{l}0,9607^{* * *} \\
(0,000019)\end{array}$ & $\begin{array}{l}1,0383 * * * \\
(0,000020)\end{array}$ & 0,9977 \\
\hline BASF SE & $\begin{array}{l}0,5899 * * * \\
(0,013401)\end{array}$ & $\begin{array}{c}10,4456^{* * *} \\
(12,166114)\end{array}$ & $\begin{array}{l}0,9094^{* * *} \\
(0,000123)\end{array}$ & $\begin{array}{l}1,0461^{* * *} \\
(0,000041)\end{array}$ & 0,9965 \\
\hline BAY. MOTOREN WERKE AG (c.s.) & $\begin{array}{c}0,2086 \\
(0,044880)\end{array}$ & $\begin{array}{c}4,7428^{* *} \\
(3,734100)\end{array}$ & $\begin{array}{l}0,8892^{* * *} \\
(0,000352)\end{array}$ & $\begin{array}{l}1,0845^{* * *} \\
(0,000294)\end{array}$ & 0,9949 \\
\hline BAYER AG & $\begin{array}{c}0,1175 \\
(0,136659)\end{array}$ & $\begin{array}{c}47,9942^{* *} \\
(449,717985)\end{array}$ & $\begin{array}{l}0,9443^{* * *} \\
(0,000039)\end{array}$ & $\begin{array}{l}1,0411^{* * *} \\
(0,000033)\end{array}$ & 0,9960 \\
\hline BEIERSDORF AG & $\begin{array}{l}0,7784 * * * \\
(0,056343)\end{array}$ & $\begin{array}{c}109,9968 \\
(5.040,095470)\end{array}$ & $\begin{array}{l}0,9367^{* * *} \\
(0,000050)\end{array}$ & $\begin{array}{l}1,0313^{* * *} \\
(0,000027)\end{array}$ & 0,9950 \\
\hline COMMERZBANK AG & $\begin{array}{c}0,4967^{* *} \\
(0,043702)\end{array}$ & $\begin{array}{c}0,3305 \\
(0,243851)\end{array}$ & $\begin{array}{l}0,6845^{* * * *} \\
(0,045003)\end{array}$ & $\begin{array}{l}1,1596^{* * *} \\
(0,017597)\end{array}$ & 0,9980 \\
\hline DAIMLER AG & $\begin{array}{c}-0,2164 \\
(0,482772)\end{array}$ & $\begin{array}{c}43,3092^{*} \\
(627,623548)\end{array}$ & $\begin{array}{l}0,9636^{* * * *} \\
(0,000019)\end{array}$ & $\begin{array}{l}1,0299 * * * \\
(0,000020)\end{array}$ & 0,9974 \\
\hline DEUTSCHE BANK AG & $\begin{array}{c}0,2543 \\
(0,038774)\end{array}$ & $\begin{array}{l}1,8519 * * * \\
(0,432202)\end{array}$ & $\begin{array}{l}0,9350^{* * *} \\
(0,000086)\end{array}$ & $\begin{array}{l}1,0495 * * * \\
(0,000075)\end{array}$ & 0,9979 \\
\hline DEUTSCHE BOERSE AG & $\begin{array}{l}0,7329 * * * \\
(0,008016)\end{array}$ & $\begin{array}{l}1,1790^{* * *} \\
(0,154737)\end{array}$ & $\begin{array}{l}0,9240^{* * *} \\
(0,000083)\end{array}$ & $\begin{array}{l}1,0287^{* * * *} \\
(0,000024)\end{array}$ & 0,9978 \\
\hline DEUTSCHE POST AG & $\begin{array}{l}0,7952^{* * *} \\
(0,072417)\end{array}$ & $\begin{array}{c}527,5659 \\
(125.357,996408)\end{array}$ & $\begin{array}{l}0,9425^{* * *} \\
(0,000040)\end{array}$ & $\begin{array}{l}1,0300^{* * *} \\
(0,000024)\end{array}$ & 0,9956 \\
\hline DEUTSCHE TELEKOM AG & $\begin{array}{c}-0,0862 \\
(0,098133)\end{array}$ & $\begin{array}{c}317,0287^{* * *} \\
(12.538,620584)\end{array}$ & $\begin{array}{l}0,9618^{* * *} \\
(0,000026)\end{array}$ & $\begin{array}{l}1,0386^{* * *} \\
(0,000029)\end{array}$ & 0,9984 \\
\hline E.ON AG & $\begin{array}{l}0,5056^{* * *} \\
(0,033217)\end{array}$ & $\begin{array}{c}32,8602^{* * *} \\
(136,342429)\end{array}$ & $\begin{array}{l}0,9500^{* * *} \\
(0,000039)\end{array}$ & $\begin{array}{l}1,0312^{* * *} \\
(0,000023)\end{array}$ & 0,9978 \\
\hline FRESEN.MED.CARE KGAA (c.s.) & $\begin{array}{c}0,0697 \\
(0,148020)\end{array}$ & $\begin{array}{c}6,0591^{*} \\
(10,476852)\end{array}$ & $\begin{array}{l}0,8986^{* * *} \\
(0,000752)\end{array}$ & $\begin{array}{l}1,0858^{* * *} \\
(0,000529)\end{array}$ & 0,9888 \\
\hline FRESENIUS SE (p.s.) & $\begin{array}{c}0,1779 \\
(0,053081)\end{array}$ & $\begin{array}{l}11,0349 * * * \\
(14,114374)\end{array}$ & $\begin{array}{l}0,9432^{* * *} \\
(0,000048)\end{array}$ & $\begin{array}{l}1,0440 * * * \\
(0,000048)\end{array}$ & 0,9975 \\
\hline HEIDELBERGCEMENT AG & $\begin{array}{l}0,6028^{* * *} \\
(0,024636)\end{array}$ & $\begin{array}{c}0,5679^{* *} \\
(0,081493)\end{array}$ & $\begin{array}{l}0,8850^{* * *} \\
(0,000430)\end{array}$ & $\begin{array}{l}1,0481 * * * \\
(0,000276)\end{array}$ & 0,9970 \\
\hline HENKEL AG \&CO KGAA (p.s.) & $\begin{array}{c}0,4634^{* *} \\
(0,035872)\end{array}$ & $\begin{array}{c}42,2867^{* * *} \\
(253,485100)\end{array}$ & $\begin{array}{l}0,9257^{* * *} \\
(0,000069)\end{array}$ & $\begin{array}{l}1,0432^{* * *} \\
(0,000042)\end{array}$ & 0,9958 \\
\hline INFINEON TECHNOLOGIES AG & $\begin{array}{l}0,4763^{* * *} \\
(0,021067)\end{array}$ & $\begin{array}{c}41,2219^{* * *} \\
(198,262469)\end{array}$ & $\begin{array}{l}0,9003^{* * *} \\
(0,000162)\end{array}$ & $\begin{array}{l}1,0529 * * * \\
(0,000120)\end{array}$ & 0,9969 \\
\hline $\mathrm{K}+\mathrm{S}$ AG & $\begin{array}{c}0,6789 \\
(0,181356)\end{array}$ & $\begin{array}{c}100,0079 \\
(9.472,241923)\end{array}$ & $\begin{array}{l}0,9722^{* * *} \\
(0,000014)\end{array}$ & $\begin{array}{l}1,0217^{* * *} \\
(0,000014)\end{array}$ & 0,9978 \\
\hline LINDE AG & $\begin{array}{c}0,4901^{* *} \\
(0,041666)\end{array}$ & $\begin{array}{c}13,5113^{* *} \\
(27,600937)\end{array}$ & $\begin{array}{l}0,9409^{* * *} \\
(0,000040)\end{array}$ & $\begin{array}{l}1,0349 * * * \\
(0,000025)\end{array}$ & 0,9968 \\
\hline LUFTHANSA AG & $\begin{array}{c}0,4188^{* *} \\
(0,044752)\end{array}$ & $\begin{array}{c}58,6607 * * \\
(638,065119)\end{array}$ & $\begin{array}{l}0,9354^{* * *} \\
(0,000123)\end{array}$ & $\begin{array}{l}1,0451^{* * *} \\
(0,000085)\end{array}$ & 0,9964 \\
\hline MAN SE (c.s.) & $\begin{array}{l}0,6584 * * * \\
(0,031407)\end{array}$ & $\begin{array}{c}7,2738^{* *} \\
(8,080573)\end{array}$ & $\begin{array}{l}0,9535^{* * * *} \\
(0,000027)\end{array}$ & $\begin{array}{l}1,0287 * * * \\
(0,000015)\end{array}$ & 0,9979 \\
\hline MERCK KGAA & $\begin{array}{l}0,4801 * * * \\
(0,025386)\end{array}$ & $\begin{array}{l}1,1107^{* *} \\
(0,237078)\end{array}$ & $\begin{array}{l}0,9076 * * * \\
(0,000290)\end{array}$ & $\begin{array}{l}1,0509 * * * \\
(0,000152)\end{array}$ & 0,9973 \\
\hline METRO AG (c.s.) & $\begin{array}{c}0,3575 \\
(0,088946)\end{array}$ & $\begin{array}{c}41,5839 * * \\
(316,530440)\end{array}$ & $\begin{array}{l}0,9508^{* * *} \\
(0,000028)\end{array}$ & $\begin{array}{l}1,0395 * * * \\
(0,000023)\end{array}$ & 0,9969 \\
\hline MUENCH. RUECKVERS. AG & $\begin{array}{l}0,5550^{* * * *} \\
(0,028974)\end{array}$ & $\begin{array}{l}3,3960 * * * \\
(1,571806)\end{array}$ & $\begin{array}{l}0,9074^{* * * *} \\
(0,000108)\end{array}$ & $\begin{array}{l}1,0446^{* * *} \\
(0,000067)\end{array}$ & 0,9943 \\
\hline RWE AG (c.s.) & $\begin{array}{l}0,5002^{* * *} \\
(0,032854)\end{array}$ & $\begin{array}{l}13,4324^{* * *} \\
(23,153506)\end{array}$ & $\begin{array}{l}0,9456^{* * *} \\
(0,000029)\end{array}$ & $\begin{array}{l}1,0374 * * * \\
(0,000020)\end{array}$ & 0,9975 \\
\hline SAP AG & $\begin{array}{c}-0,5612 \\
(0,893932)\end{array}$ & $\begin{array}{c}185,2925^{*} \\
(10.647,624583)\end{array}$ & $\begin{array}{l}0,9535^{* * *} \\
(0,000033)\end{array}$ & $\begin{array}{l}1,0487^{* * *} \\
(0,000039)\end{array}$ & 0,9951 \\
\hline SIEMENS AG & $\begin{array}{c}0,3759 \\
(0,066923)\end{array}$ & $\begin{array}{c}5,7225^{* *} \\
(5,873838)\end{array}$ & $\begin{array}{l}0,9463^{* * *} \\
(0,000041)\end{array}$ & $\begin{array}{l}1,0356^{* * *} \\
(0,000033)\end{array}$ & 0,9966 \\
\hline THYSSENKRUPP AG & $\begin{array}{c}-2,4694 \\
(20,374941)\end{array}$ & $\begin{array}{c}332,5254 \\
(89.305,542038)\end{array}$ & $\begin{array}{l}0,9598^{* * * *} \\
(0,000021)\end{array}$ & $\begin{array}{l}1,0290 * * * \\
(0,000017)\end{array}$ & 0,9970 \\
\hline VOLKSWAGEN AG (p.s.) & $\begin{array}{c}0,1959 \\
(0,513363)\end{array}$ & $\begin{array}{c}17,4221 \\
(221,431663)\end{array}$ & $\begin{array}{l}0,9854^{* * *} \\
(0,000009)\end{array}$ & $\begin{array}{l}1,0155^{* * *} \\
(0,000009)\end{array}$ & 0,9988 \\
\hline
\end{tabular}

The table provides the estimated coefficients of the non linear least squares regression for the stocks that were included in the DAX30 as of Dec $31^{\text {st }}$ 2010. Common stocks are marked with "c.p.", preferred stocks are indicated by "p.s.". The difference between the magnitude of social influence of fundamentalists $\delta_{F}$ and chartists $\delta_{C}$ results from $\Delta \delta^{*}=\frac{\delta_{F}-\delta_{C}}{1-\delta_{C}}$. The intensity of choice, measuring investors' tendency to choose the strategy which has better performed in the past, divided by investors' constant rate of risk aversion and the expected price volatility is given by $\beta^{*}=\frac{\beta}{a \sigma^{2}}$. The coefficients $\Phi_{F}$ and $\Phi_{C}$ are the factors that fundamentalists and chartists use to form their expectations based on the past deviation of the asset price from its fundamental benchmark. The significance of coefficients is indicated by stars $\left({ }^{*} p<0.1,{ }^{* *} p<0.05,{ }^{* * *} p<0.01\right)$. The corresponding standard deviations are reported in parenthesis. 
from zero. Hence, for more than half of the stocks, the influence from social interaction explains a part of the stock price fluctuations around its fundamental benchmark. Interestingly, in all of these cases, the estimates of $\Delta \delta^{*}$ are greater than zero, which indicates that $\delta_{F}$ is greater than $\delta_{C}$. Hence, fundamentalists skew their beliefs more strongly into the direction of chartists than chartists do into the opposite direction. Therefore, it can be concluded that social interaction rather has a destabilising impact on financial markets. Overall, one can state that social influence at least does not have a stabilising effect.

\section{Conclusion}

In this paper, I introduced an asset pricing model that takes the influence from social interaction into account. The framework is based on the adaptive beliefs system of Brock and Hommes (1998). Empirically analysing all stocks in the DAX30 index as of Dec $31^{\text {st }} 2010$, I found that social influence explains a part of the fluctuations of the stock price around its fundamental benchmark for more than half of the stocks. Moreover, my results suggest that social interaction rather has a destabilising impact on stock prices. At least, one can state that it does not have a stabilising effect.

\section{Appendix}

\section{A.1. Equilibrium condition}

All propositions in chapter 3.2 refer to conditions that if fulfilled lead to exactly one equilibrium market price given by equation 9 . Such an equilibrium is obtained, if equation 11 has exactly one feasible solution for the vector of investors' beliefs $\mathbf{f}_{t}=\left(f_{1 t}, f_{2 t}, \ldots, f_{i t}, \ldots, f_{N t}\right)^{T}$. For notational convenience, equation 11 can be written in the vectorial form:

$$
\mathbf{f}_{t}=\theta_{t}+\mathbf{D}\left(\boldsymbol{\Gamma} \mathbf{f}_{t}-\theta_{t}\right)
$$

where $\boldsymbol{\theta}_{t}=\left(\theta_{1 t}, \theta_{2 t}, \ldots, \theta_{i t}, \ldots, \theta_{N t}\right)^{T}$ and the matrices $\mathbf{D}$ and $\boldsymbol{\Gamma}$ are given by

$$
\mathbf{D}=\left[\begin{array}{cccccc}
\delta_{1} & 0 & \ldots & 0 & \ldots & 0 \\
0 & \delta_{2} & \ldots & 0 & \ldots & 0 \\
\vdots & \vdots & \ddots & \vdots & \ddots & \vdots \\
0 & 0 & \ldots & \delta_{i} & \ldots & 0 \\
\vdots & \vdots & \ddots & \vdots & \ddots & \vdots \\
0 & 0 & \ldots & 0 & \ldots & \delta_{N}
\end{array}\right]
$$


and

$$
\boldsymbol{\Gamma}=\left[\begin{array}{cccccc}
0 & \gamma_{12} & \ldots & \gamma_{1 j} & \ldots & \gamma_{1 N} \\
\gamma_{21} & 0 & \ldots & \gamma_{2 j} & \ldots & \gamma_{2 N} \\
\vdots & \vdots & \ddots & \vdots & \ddots & \vdots \\
\gamma_{i 1} & \gamma_{i 2} & \ldots & 0 & \ldots & \gamma_{i N} \\
\vdots & \vdots & \ddots & \vdots & \ddots & \vdots \\
\gamma_{N 1} & \gamma_{N 2} & \ldots & \gamma_{N j} & \ldots & 0
\end{array}\right]
$$

Solving equation 38 for $\mathbf{f}_{t}$ ones obtains

$$
\mathbf{f}_{t}=\mathbf{M}^{-1}(\mathbf{I}-\mathbf{D}) \theta_{t},
$$

where $\mathbf{I}$ is the identity matrix and $\mathbf{M}$ is given by

$$
\mathbf{M}=\mathbf{I}-\mathbf{D} \boldsymbol{\Gamma}=\left[\begin{array}{cccccc}
1 & -\delta_{1} \gamma_{12} & \ldots & -\delta_{1} \gamma_{1 j} & \ldots & -\delta_{1} \gamma_{1 N} \\
-\delta_{2} \gamma_{21} & 1 & \ldots & -\delta_{2} \gamma_{2 j} & \ldots & -\delta_{2} \gamma_{2 N} \\
\vdots & \vdots & \ddots & \vdots & \ddots & \vdots \\
-\delta_{i} \gamma_{i 1} & -\delta_{i} \gamma_{i 2} & \ldots & 1 & \ldots & -\delta_{i} \gamma_{i N} \\
\vdots & \vdots & \ddots & \vdots & \ddots & \vdots \\
-\delta_{N} \gamma_{N 1} & -\delta_{N} \gamma_{N 2} & \ldots & -\delta_{N} \gamma_{N j} & \ldots & 1
\end{array}\right]
$$

Equation 41 yields exactly one solution for $\mathbf{f}_{t}$, if the following condition is met:

$$
\operatorname{Det}(\mathbf{M}) \neq 0 .
$$

Hence, if the determinant of $\mathbf{M}$ is unequal to zero, equation 9 leads to exactly one equilibrium market price.

\section{A.2. Proof of proposition 1}

In order to give the proof of proposition 1 , it has to be shown that the determinant of $\mathbf{M}$ is always unequal to zero, if all $\delta_{i}$ are smaller than one. If $\delta_{i}<1$, then $\mathbf{M}$ has a dominant diagonal, because constraint 12 ensures that for each row

$$
1>\sum_{j \neq i}\left|-\delta_{i} \gamma_{i j}\right|
$$

is fulfilled. Therefore, the determinant of $\mathbf{M}$ is unequal to zero (Taussky, 1949). 


\section{A.3. Proof of proposition 2}

If one allows $\delta_{i}$ to be greater than one for some investors, then the matrix M no longer has a dominant diagonal as stated in the proof of proposition 1. If however additionally a network structure with equal weights $\left(\gamma_{i j}=\frac{1}{N-1}\right)$ is presumed, then $\mathbf{M}$ can be reformulated, such that still a dominant diagonal is obtained. Multiplying the rows of a matrix with a factor unequal to zero only scales the determinant by this factor, but never induces the determinant to become equal or unequal to zero. Therefore, the rows of the matrix $\mathbf{M}$ where $\delta_{i}>1$ are multiplied by $\frac{1}{\delta_{i}}$. In order to demonstrate this, assume a market with four investors where $\delta_{1}>1, \delta_{2}<1, \delta_{3}>1$ and $\delta_{4}<1$. After multiplication, the matrix $\mathbf{M}$ is given by

$$
\mathbf{M}=\left[\begin{array}{cccc}
\frac{1}{\delta_{1}} & -\frac{1}{N-1} & -\frac{1}{N-1} & -\frac{1}{N-1} \\
-\delta_{2} \frac{1}{N-1} & 1 & -\delta_{2} \frac{1}{N-1} & -\delta_{2} \frac{1}{N-1} \\
-\frac{1}{N-1} & -\frac{1}{N-1} & \frac{1}{\delta_{3}} & -\frac{1}{N-1} \\
-\delta_{4} \frac{1}{N-1} & -\delta_{4} \frac{1}{N-1} & -\delta_{4} \frac{1}{N-1} & 1
\end{array}\right] .
$$

Looking at the rows where $\delta_{i}>1$, it can be seen that the conditions for a dominant diagonal are not fulfilled, because

$$
\frac{1}{\delta_{i}}<\sum_{j \neq i}\left|-\frac{1}{N-1}\right|=1 \text { for } \delta_{i}>1 .
$$

However, regarding the columns of the resulting matrix, there are two kinds of conditions that if fulfilled ensure a dominant diagonal. For those investors where $\delta_{i}<1$ the diagonal element still is one as those rows remained unchanged by the multiplication. The conditions for the columns where the diagonal element is one is given by

$$
1>\sum_{j \neq i}\left|-\min \left\{\delta_{j}, 1\right\} \frac{1}{N-1}\right| .
$$

This is always fulfilled, if there are at least two investors who are only moderately influenced $\left(\delta_{i}<1\right)$. The condition for investors where $\delta_{i}>1$ is given by

$$
\begin{aligned}
& \frac{1}{\delta_{i}}>\sum_{j \neq i}\left|-\min \left\{\delta_{j}, 1\right\} \frac{1}{N-1}\right| \\
& \delta_{i}<\frac{1}{\sum_{j \neq i}\left|-\min \left\{\delta_{j}, 1\right\} \frac{1}{N-1}\right|}
\end{aligned}
$$


If this is met for all investors with $\delta_{i}>1$, then a dominant diagonal is ensured and hence the determinant of $\mathbf{M}$ is unequal to zero.

\section{A.4. Proof of proposition 3}

If there are only two investor types with specific values for the magnitude of social influence $\left(\delta_{1}\right.$ and $\left.\delta_{2}\right)$ and the network structure still consists of equal weights $\left(\gamma_{i j}=\frac{1}{N-1}\right)$, then the equilibrium conditions of proposition 2 can be stated more precisely. Particularly, the matrix $\mathbf{M}$ is then given by

$$
\mathbf{M}=\left[\begin{array}{cccccc}
1 & \ldots & -\delta_{1} \gamma_{1 j} & -\delta_{1} \gamma_{1(j+1)} & \ldots & -\delta_{1} \gamma_{1 N} \\
\vdots & \ddots & \vdots & \vdots & \ddots & \vdots \\
-\delta_{1} \gamma_{K 1} & \ldots & 1 & -\delta_{1} \gamma_{K(j+1)} & \ldots & -\delta_{1} \gamma_{K N} \\
\hline-\delta_{2} \gamma_{(K+1) 1} & \ldots & -\delta_{2} \gamma_{(K+1) j} & 1 & \ldots & -\delta_{2} \gamma_{(K+1) N} \\
\vdots & \ddots & \vdots & \vdots & \ddots & \vdots \\
-\delta_{2} \gamma_{N 1} & \ldots & -\delta_{2} \gamma_{N j} & -\delta_{2} \gamma_{N(j+1)} & \ldots & 1
\end{array}\right]
$$

where $K$ is number of first type investors. The determinant of $\mathbf{M}$ turns out to be

$$
\begin{aligned}
\operatorname{Det}(\mathbf{M}) & =(-1)^{(N-1)}\left(\frac{\delta_{1}}{N-1}+1\right)^{(K-1)}\left(\frac{\delta_{2}}{N-1}+1\right)^{(N-K-1)} \\
& \left(-1+\frac{K \delta_{1}}{N-1}+\frac{(N-K) \delta_{2}}{N-1}-\frac{\delta_{1}+\delta_{2}-\delta_{1} \delta_{2}}{N-1}\right)
\end{aligned}
$$

As $\delta_{i} \geq 0$, the determinant of $\mathbf{M}$ is always unequal to zero, if the last term of equation 50 is unequal to zero. Hence,

$$
\frac{K \delta_{1}}{N-1}+\frac{(N-K) \delta_{2}}{N-1}-\frac{\delta_{1}+\delta_{2}-\delta_{1} \delta_{2}}{N-1} \neq 1
$$

As $N$ tends towards infinity, equation 51 becomes

$$
n \delta_{1}+(n-1) \delta_{2} \neq 1,
$$

with $n=\frac{K}{N}$. 


\section{References}

Alfarano, S., Lux, T., Wagner, F., 2005. Estimation of agent-based models: The case of an asymmetric herding model. Computational Economics 26, 19-49.

Alfarano, S., Lux, T., Wagner, F., 2008. Time-variation of higher moments in a financial market with heterogeneous agents: An analytical approach. Journal of Economic Dynamics and Control 32 (1), 101-136.

Amilon, H., 2008. Estimation of an adaptive stock market model with heterogeneous agents. Journal of Empirical Finance 15, 342-362.

ap Gwilym, R., 2008. Simulating asset prices under behavioural assumptions. Working Paper, Bangor University.

Arnswald, T., 2001. Investment behaviour of german equity fund managers: An exploratory analysis of survey data. Deutsche Bundesbank Discussion Paper 08/01.

Baker, W. E., Iyer, A. V., 1992. Information networks and market behavior. Journal of Mathematical Sociology 16 (4), 305-332.

Beja, A., Goldman, M. B., 1980. On the dynamic behavior of prices in disequilibrium. Journal of Finance 35, 235-248.

Bernhardt, D., Campello, M., Kusoati, E., 2006. Who herds? Journal of Financial Economics 80 (3), 657-675.

Blume, L. E., Brock, W. A., Durlauf, S. N., Ioannides, Y. M., 2010. Identification of social interactions. in: Handbook of social economics, J. Benhabib, A. Bisin and M. Jackson (eds.), Elsevier.

Boswijk, H. P., Hommes, C. H., Manzan, S., 2007. Behavioral heterogeneity in stock prices. Journal of Economic Dynamics and Control 31, 1938-1970.

Bramoullé, Y., Djebbari, H., Fortin, B., 2009. Identification of peer effects through social networks. Journal of Econometrics 150, 41-55.

Brock, W. A., Durlauf, S. N., 2001a. Discrete choice with social interactions. Review of Economic Studies 68, 235-260. 
Brock, W. A., Durlauf, S. N., 2001b. The econometrics of interactions-based models. in: Handbook of econometrics, J. Heckman and E. Leamer (eds.), North-Holland, Amsterdam.

Brock, W. A., Hommes, C. H., 1997. A rational route to randomness. Econometrica 65 (5), 1059-1095.

Brock, W. A., Hommes, C. H., 1998. Heterogeneous beliefs and routes to chaos in a simple asset pricing model. Journal of Economic Dynamics and Control 22, 1235-1274.

Chang, S.-K., 2007. A simple asset pricing model with social interactions and heterogeneous beliefs. Journal of Economic Dynamics and Control 31, $1300-1325$.

Chen, Q., Jiang, W., 2006. Analysts' weighting of private and public information. Review of Financial Studies 19 (1), 319-355.

Chiarella, C., 1992. The dynamics of speculative behaviour. Annals of Operations Research 37, 101-123.

Chiarella, C., Gallegati, M., Leombruni, R., Palestrini, A., 2003. Asset price dynamics among heterogeneous interacting agents. Computational Economics 22, 213-223.

Cipriani, M., Guarino, A., 2008. Herd behavior and contagion in financial markets. B.E. Journal of Theoretical Economics 8 (1), Art. 24.

Clarke, J., Subramanian, A., 2006. Dynamic forecasting behavior by analysts: Theory and evidence. Journal of Financial Economics 80 (1), 81-113.

Colla, P., Mele, A., 2010. Information linkages and correlated trading. Review of Financial Studies 23 (1), 203-246.

Cont, R., Bouchaud, J.-P., 2000. Herd behavior and aggregate fluctuations in financial markets. Macroeconomic Dynamics 4, 170-196.

Cooper, R. A., Day, T. E., Lewis, C. M., 2001. Following the leader: A study of individual analysts earnings forecasts. Journal of Financial Economics 61 (3), 383-416. 
Day, R. H., Huang, W., 1990. Bulls, bears and market sheep. Journal of Economic Behavior and Organization 14 (3), 299-329.

de Grauwe, P., Grimaldi, M., 2004. Bubbles and crashes in a behavioural finance model. Working Paper No. 164, Riksbank Research Paper Series No. 7.

Dieci, R., Foroni, I., Gardini, L., He, X.-Z., 2006. Market mood, adaptive beliefs and asset price dynamics. Chaos, Solitons \& Fractals 29 (3), 520534 .

Fama, E. F., 1970. Efficient capital markets: A review of theory and empirical work. Journal of Finance 25, 383-417.

Föllmer, H., Horst, U., Kirman, A., 2005. Equilibria in financial markets with heterogeneous agents: A probabilistic perspective. Journal of Mathematical Economics 41 (1-2), 123-155.

Föllmer, H., Schweizer, M., 1993. A microeconomic approach to diffusion models for stock prices. Mathematical Finance 3, 1-23.

Franke, R., 2008. A microfounded herding model and its estimation on german survey expectations. European Journal of Economics and Economic Policies 5, 301-328.

Franke, R., 2009. Applying the method of simulated moments to estimate a small agent-based asset pricing model. Journal of Empirical Finance 16, 804-815.

Frankel, J. A., Froot, K. A., 1988. Chartists, fundamentalists and the demand for dollars. Greek Economic Review 10 (1), 49-102.

Frey, S., Herbst, P., Walter, A., 2006. Measuring mutual fund herding - a structural approach. Working Paper, Goethe-University Frankfurt.

Gilli, M., Winker, P., 2003. A global optimization heuristic for estimating agent based models. Computational Statistics and Data Analysis 42, 299312 .

Glaeser, E. L., Sacerdote, B. I., Scheinkman, J. A., 2003. The social multiplier. Journal of the European Economic Association 1 (2-3), 345-353. 
Glaeser, E. L., Scheinkman, J. A., 2001. Non-market interaction. in: Advances in Economics and Econometrics: Theory and Application, Eight World Congress, M. Dewatripont, L. P. Hansen and S. J. Turnovsky (eds.), Cambridge University Press, 339-374.

Graham, J. R., 1999. Herding among investment newsletters: Theory and evidence. Journal of Finance 54 (1), 237-268.

Hirshleifer, D., Teoh, S. H., 2008. Thought and behavior contagion in capital markets. in: Handbook of Financial Markets: Dynamics and Evolution, Thorsten Hens and Klaus Reiner Schenk-Hoppé (eds.), Elsevier.

Hommes, C., 2006. Heterogeneous agent models in economics and finance. in: Handbook of Computational Economics, K. L. Judd and L. Tesfatsion (eds.), Elsevier.

Hong, H., Kubic, J. D., Stein, J. C., 2004. Social interaction and stock market participation. Journal of Finance 59 (1), 137-163.

Hong, H., Kubik, J. D., 2003. Analyzing the analysts: Career concerns and biased earnings forecasts. Journal of Finance 58 (1), 313-351.

Hong, H., Kubik, J. D., Solomon, A., 2000. Security analysts' career concerns and herding of earnings forecasts. RAND Journal of Economics 31 (1), $121-144$.

Hong, H., Kubik, J. D., Stein, J. C., 2005. Thy neighbor's portfolio: Wordof-mouth effects in the holdings and trades of money managers. Journal of Finance 60, 2801-2824.

Horst, U., 2005. Financial price fluctuations in a stock market model with many interacting agents. Economic Theory 25, 917-932.

Horst, U., Rothe, C., 2008. Queuing, social interactions, and the microstructure of financial markets. Macroeconomic Dynamics, Cambridge University Press 12, 211-233.

Hsieh, S.-F., 2012. Individual and institutional herding and the impact on stock returns: Evidence from taiwan stock market. Working Paper, National Kaohsiung First University of Science and Technology. 
Huang, W., Zheng, H., Chia, W.-M., 2010. Financial crises and interacting heterogeneous agents. Journal of Economic Dynamics and Control 34, $1105-1122$.

Iori, G., 2002. A microsimulation of traders' activity in the stock market: The role of heterogeneity, agents' interactions and trade frictions. Journal of Economic Behavior and Organization 49, 269-285.

Ivkovic, Z., Weisbenner, S., 2007. Information diffusion effects in individual investors' common stock purchases: Covet thy neighbors' investment choices. Review of Financial Studies 20 (4), 1327-1357.

Jegadeesh, N., Kim, W., 2010. Do analysts herd? an analysis of recommendations and market reactions. Review of Financial Studies 23 (2), 901-937.

Jones, S. L., Lee, D., Weis, E., 1999. Herding and feedback trading by different types of institutions and the effects on stock prices. Review of Financial Studies 7, 631-652.

Kaizoji, T., 2000. Speculative bubbles and crashes in stock markets: an interacting-agent model of speculative activity. Physica A 287 (3-4), 493506.

Kirman, A., 1993. Ants, rationality, and recruitment. Quarterly Journal of Economics 108, 137-156.

Kurz, M., 1998. Social states of belief and the determinants of the equity risk premium in a rational belief equilibrium. Working Paper, Stanford University.

Kyle, A. S., 1985. Continuous auctions and insider trading. Econometrica 53 (6), 1315-1335.

Lakonishok, J., Shleifer, A., Vishny, R. W., 1992. The impact of institutional trading on stock prices. Journal of Financial Economics 31, 23-43.

LeBaron, B., 2006. Agent-based computational finance. in: Handbook of Computational Economics, K. L. Judd and L. Tesfatsion (eds.), Elsevier.

Lee, L.-F., Liu, X., Lin, X., 2010. Specification and estimation of social interaction models with network structures. Econometrics Journal 13 (2), 145-176. 
Long, J. B. D., Shleifer, A., Summers, L. H., Waldmann, R. J., 1990. Noise trader risk in financial markets. Journal of Political Economy 98, 703-738.

Lux, T., 1995. Herd behaviour, bubbles and crashes. Economic Journal 105, 881-896.

Lux, T., 1998. The socio-economic dynamics of speculative markets interacting agents, chaos, and the fat tails of return distributions. Journal of Economic Behavior and Organization 33, 143-165.

Lux, T., 2009. Stochastic behavioral asset pricing models and the stylized facts. in: Handbook of Financial Markets: Dynamics and Evolution, Thorsten Hens and Klaus Reiner Schenk-Hoppé (eds.), Elsevier.

Lux, T., 2012. Estimation of an agent-based model of investor sentiment formation in financial markets. Journal of Economic Dynamics and Control $36,1284-1302$.

Manski, C., 1993. Identification of endogenous social interactions: The reflection problem. Review of Economic Studies 60 (3), 531-542.

Manzan, S., Westerhoff, F., 2005. Representativeness of news and exchange rate dynamics. Journal of Economic Dynamics and Control 29, 677-689.

Massa, M., Simonov, A., 2005a. Do bubbles have a birthdate? the role of college interaction in portfolio choice. Working Paper, INSEAD, CEPR and Stockholm School of Economics.

Massa, M., Simonov, A., 2005b. History versus geography: The role of college interaction in portfolio choice and stock market prices. EFA 2005 Moscow Meetings Paper.

Moffitt, R. A., 2001. Policy interventions low-level equilibria and social interactions. in: Social Dynamics, S. Durlauf and P. Young (eds.), MIT Press.

Naujoks, M., Aretz, K., Kerl, A., Walter, A., 2009. Do german security analysts herd? Financial Markets and Portfolio Management 23 (1), 3-29.

Nofsinger, J. R., Sias, R. W., 1999. Herding and feedback trading by institutional and individual investors. Journal of Finance 54 (6), 2263-2295. 
Ozsoylev, H. N., 2006. Asset pricing implications of social networks. Working Paper, University of Oxford.

Ozsoylev, H. N., Walden, J., 2011. Asset pricing in large information networks. Journal of Economic Theory 146, 2252-2280.

Pakkanen, M. S., 2009. Microfoundations for diffusion price processes. Working Paper, University of Helsinki.

Panchenko, V., Gerasymchuk, S., Pavlov, O. V., 2010. Asset price dynamics with local interactions under heterogeneous beliefs. Working Paper, University of New South Wales.

Pareek, A., 2011. Information networks: Implications for mutual fund trading behavior and stock returns. Working Paper, Rutgers University.

Puckett, A., Yan, X., 2008. Short-term institutional herding and its impact on stock prices. Working Paper, University of Missouri.

San, G., 2007. Who gains more by trading - institutions or individuals? Working Paper, Tel-Aviv University.

Schütz, G. M., de Almeida Prado, F. P., Harris, R. J., Belitsky, V., 2009. Short-time behaviour of demand and price viewed through an exactly solvable model for heterogeneous interacting market agents. Physica A 388, 4126-4144.

Shiller, R. J., 1984. Stock prices and social dynamics. Brookings Papers in Economic Activity 2, 457-510.

Shiller, R. J., Pound, J., 1989. Survey evidence on diffusion of interest and information among investors. Journal of Economic Behavior and Organization $12,47-66$.

Sias, R. W., 2004. Institutional herding. Review of Financial Studies 17, 165-206.

Taussky, O., 1949. A recurring theorem on determinants. American Mathematical Monthly 56 (10), 672-676. 
Vigfusson, R., 1997. Switching between chartists and fundamentalists: A markov regime-switching approach. International Journal of Finance and Economics 2, 291-305.

Walter, A., Weber, F. M., 2006. Herding in the german mutual fund industry. European Financial Management 12 (3), 375-406.

Welch, I., 2000. Herding among security analysts. Journal of Financial Economics 58, 369-396.

Wermers, R., 1999. Mutual fund herding and the impact on stock prices. Journal of Finance 54 (2), 581-622.

Westerhoff, F. H., Reitz, S., 2003. Nonlinearities and cyclical behavior: The role of chartists and fundamentalists. Studies in Nonlinear Dynamics and Econometrics 7, 1-12.

Wu, B., 2007. Interacting agent feedback finance model. Working Paper, McMaster University. 